\title{
Study of the Standard Insurance Provisions' Interpretation
}

\author{
Yang Yang \\ Southwest University, Chongqing, China \\ Email: yangyangtangxin@vip.qq.com
}

Received 18 November 2013; revised 22 December 2013; accepted 2 January 2014

Copyright (C) 2014 by author and Scientific Research Publishing Inc.

This work is licensed under the Creative Commons Attribution International License (CC BY). http://creativecommons.org/licenses/by/4.0/

(c) (i) Open Access

\begin{abstract}
The new insurance law has been implemented for a long time, but it is still disputed frequently for the application of standard insurance clause. We can see this from many cases, e.g. the Sued People's Insurance Company of China LLC, Jinyun Branch office Insurance contract Dispute Case by Li Shangzhi. This paper is trying to take the standard insurance clause as the beginning point to briefly analyze the reason for the terms' understanding differences and to study their unfavorable interpretation principle through comparing the provisions' samples in the old and new insurance law, which can be looked forward to providing some ideas for their corresponding practice.
\end{abstract}

\section{Keywords}

The Standard Insurance Provision; The Interpretation Principle; The Type of Interpretation; The Unfavorable Interpretation Principle

\section{Introduction}

The significance of insurance system is aimed at gathering force to form the community to share the risk and disperse or digest the danger to eventually get the economic compensation when the insurable interest of the insurant is in risk. The insurance contract is a link to collect power, while the insurance provisions constitute the insurance contract. In fact, most of the provisions in contract are standard, which brings convenience and high efficiency for the insurance commercial contract. The standard insurance provisions will become the main part of the insurance contract even from the perspective of improving transaction efficiency and saving transaction costs, or conforming to the large-scale and professional development in the insurance industry, or from the need to continue its operation. Its appearance has its necessity in economy. It reflects that the modern production and business activities possess characteristics of high speed, low cost and high benefit, and it also embodies the strict scientificalness and complexity in the professional division [1]. At the same time, as the language's obscure, 
fuzzy, and other ambiguous phenomenon of the words itself in contract and mixing itself profession of insurance industry into the contract, it will led the great majority of the insurant hard to understand the specialized terminology in the provisions neither from the insurance's professional point nor from the general semantic perspective. So, it is often seen in such cases that the understanding differences for the standard provisions is covered by the external consensus when the two parties enter into an agreement, and it is inevitable for dispute and discord between them in the process of the contract's performance, especially after the insurance object in the risk.

From the case of the Sued People's Insurance Company of China LLC, Jinyun Branch office Insurance contract Dispute Case by Li Zhishang [2], we can see that the insurance system looks very beautiful like a castle in the air and lens in months and is actually no value at all. Can't they achieve their agreement's provisions instead of the standard insurance provisions through the mutual consultation, compromise?

\section{How to Explain the Standard Provisions}

\subsection{The Unfavorable Interpretation Principle of Provisions and Its Defects in the Original Insurance Law}

It is often used for the unfavorable interpretation principle in insurance law except the basic principle for the interpretation's expressionist of provisions. The unfavorable interpretation principle for the standard provision is also called the principle of doubt interpretation, which originated from the Roman law that is unfavorable for a speaker in doubt. It is subsequently accepted in the field of law. And it was introduced in the United Kingdom in 1536 as a case. Not only the law proverb is so called that it is unfavorable for user to explain it when the standard's language is in doubt, and also it is adopted in the Anglo-American law system and continental law system. In the insurance contract, it refers to that it will be unfavorable for the insurer to explain for the words or provisions used in the insurance contract when their disputes for the insurance provisions in contract happen between the insurers and the insurant, the insured or beneficiary [3]. Currently, this principle is established and adopted in insurance legislation or judicial precedents by most countries of the world.

According to the provisions of the article $31^{\text {st }}$ of the revised insurance law in 2002, it is not difficult to find the biggest legislative defects is that it is not limited in the premise condition and the scope for the standard provision's application-favorable to the insured and the beneficiary to explain or unfavorable to the insurer's interpretation principle for the provisions. This would led some judicial judgment authorities to explain out of context and too radical when they applied the original insurance law to interpret the insurance provisions. As long as their disputes was occurred for the insurance contract and there are ambiguities for the insurance clauses between the two parties, all should be based on the regulations of the article $31^{\text {st }}$ of original insurance law-the interpretation favorable for the insured and beneficiary to make unfavorable interpretation and make the final judgment to the insurer. This judgment is usually called adjudication of justice according to law by people without hesitation. As the legislative defects of the article $31^{\text {st }}$ of original insurance law and the thought adjudication of justice according to law, it is not only directly lead that some wrong judgments for the dispute cases of insurance contract will be occurred, but also the final for the above wrong judgments' conclusion can be difficult to find. In judicial practice, if the above wrong judgments' conclusion have been made by the first-level tribunals, it would be usually difficult to get correction through the second procedure, the procedure for trial supervision and the cancellation procedure of arbitration [4], and will make the insurer's right to be unable to get relief.

\subsection{Precondition for Its Application}

After the introduction of the new insurance law, the primary article $31^{\text {st }}$ of original insurance law was sharply revised in the article $30^{\text {st }}$ of the new insurance law, it is clearly regulated to the interpretation of the insurance contract, that it should be explained in accordance with the general understanding if their disputes were occurred between the insurer and the insurant, the insured or the beneficiary for the contract that was signed by adopting the standard clause provided by the insurer. And the people's court or the arbitration institution should make interpretation favorable to the policyholder and the beneficiary if there are two or more interpretations for the contract provisions. This new provisions is very conducive to the insurant, the insured and the beneficiary, but also conducive to the insurer. But the most obvious flaw in this article is that the reasonable relevant interpretation for the general understanding is not be made. Maybe it can only be judged according to the foregoing, that the 
understanding deviation for it mainly expressed in three levels. Firstly, the general understanding differences was usually resulted by the languages' meaning itself is obscure, vague and ambiguous. Secondly, by the context, systems, profession and non-profession. Thirdly, by the business' customary rules and historical factors. According to the article $30^{\text {st }}$ of the new insurance law, the people's court or arbitration institution should be made explanation favorable to the insured and the beneficiary from the first understanding differences level. Otherwise, the parties have to find solutions according to the legislative purpose and the specific condition of the insurance provision. So, it provides a means or ways for the unfavorable interpretation principle only to explain the ambiguous provisions in the contract insurance, and it itself can neither replace the general principles of the contract's interpretation and nor provide an method to explain the contract. And it cannot further rule out the general principle or the method's application to interpret the contract and to explain unfavorable to the insurer for the formatted clause's arbitrary. Therefore, the interpretation should be made against the insurer if there is controversy for the insurance contract. However, the unfavorable interpretation principle should be based on the general principles and basic methods of the contract interpretation as the foundation, and it can only be used in the circumstances that the text semantic meaning of the contract is unclear or it has more than one meaning-they are collectively referred to ambiguity. When the text semantic's meaning of the contract and the parties' intentions to sign a contract is clear and the contract provisions is regulated in the law, the unfavorable interpretation principle would not be introduced even if their dispute for the contract was occurred between the parties [5].

\section{The Scope for Its Application}

Although it makes the social stratification more intense as the deepening of market economy, the insurant and the insured can be roughly divided into two categories from the perspective of negotiation ability and the bargaining's power or weak - the weak for bargaining and the strong for bargaining. The weak for bargaining are mainly formed by individual insurant and the insured in a general sense, the strong for bargaining tend to be a legal person or organization of the strong business groups in economy, who have a relatively rich experience on the insurance business, or at least have the corresponding professional practitioners and internal institutions. There are two different opinions based on the insurance behavior of these two subjects - to defend and to support. In the United States, the judges who support the opinions to defend believe that it has been clearly seen before signing the insurance contract by such experienced policyholder, although the insurer does not explain the disclaimer clause, so the favorable interpretation principle does not applied for the policyholder. Some judges even believe that the favorable interpretation principle should not apply for the policyholder if the brokers or other agent of the experienced policyholder participate in negotiating the policy, or even if they do not participate in drafting the contract. Those who support the opinion think that their difference is only embodied on the quantity between these policyholders and the ordinary consumers, although the policyholders as a larger company will undoubtedly bargain when they purchase the insurance and there are great profits in bargaining for them. So, it is impossible to draft the policy for them like the ordinary consumers, and they must adopt the contract's copy provided by the insurer. The authority of the broker and agent on behalf of the larger company's interests is only on the basis of the comparison to choose to purchase the policy or choose the contract interests on the policy endorsement [5]. Actually, the unfavorable interpretation principle's introduce is because there are a lot of the insurant and the insured who are weak in economic ability and professional ability and that their interests are lost by the professional standard provisions in the practice from the view of function. For the relative part of the standard insurance provision, once there are the insurance professionals or even the internal institutions, the lawyers and the insurance brokers who are well versed in the insurance business to engage in singing the policy contract, their ability to bargain and control gradually begin to balance for both. In the insurance practice for recent years, the handwriting policy have also been appeared in some insurance companies in order to meet the special needs of the insurant except a large number of the standard insurance contract drawn up by the insurers. Thus it can be seen that the scope of its application should be narrowed and tend to the weak for bargaining from the perspective of the autonomy following the subject of market rules. When this principle is applied, at least, the factor of their bargaining abilities for the insurant and the insured should be fully considered. Therefore, we suggests that the following factors will be refereed when the unfavorable principle are applied in the new insurance law. Firstly, the insurant and the insured have or have not a considerable insurance experience like the insurer. Secondly, whether the insurant and the insured is a legal person, whether their bargaining abili- 
ties for the insurant, the insured and the insurer is comparable. Thirdly, whether the broker or professional lawyers engages in the contracting process and so on. These factors will be considered as the important factors to make discretion by court.

\section{Conclusion}

In the case of Sued People's Insurance Company of China LLC Jinyun Branch office Insurance contract Dispute Case by Li Zhishang, the court had fully considered the parties' bargaining ability from the general understanding. When this principle is applied, at least, the factor of their bargaining abilities for the insurant and the insured should be fully considered. Therefore, we suggest that the following factors will be refereed when the unfavorable principles are applied in the new insurance law. Firstly, the insurant and the insured have or have not a considerable insurance experience like the insurer. Secondly, whether the insurant and the insured is a legal person, whether their bargaining abilities for the insurant, the insured and the insurer are comparable. Thirdly, whether the broker or professional lawyers engage in the contracting process and so on. These factors will be considered as the important factors to make discretion by court. According to the regulations for the article $30^{\text {th }}$ of Insurance Act - the people's court or an arbitration institution should made interpretation favorable to the insured and the beneficiary if there are two or more explanation for the contract provisions and the $41^{\text {st }}$ of Insurance Act-it should be made interpretation accordance with the general understanding when their dispute happens for the standard clause's understanding. It should be made interpretation unfavorable to the party who provide the standard provision if there are two or more explanation for the provision, the court think it should be made interpretation favorable to the insured that the injured Yao Daoyou is wether a third party. The court finally judge Li Zhishang to win [1].

\section{References}

[1] Wang, L.M. (2002) The Law Research for Contract. 2nd Edition, China Renmin University Press Ltd., Beijing.

[2] The Magic Weapon of Peking University (2009) Zhejiang Jinyun County People's Court Civil Written Judgment 2009 Li Red Business Character No. 984. http://vip.chinalawinfo.com

[3] Shi, W.S. (1985) General Expositions of Insurance Law. 2nd Edition, San Min Book Press Ltd., Taiwan.

[4] Ren, Y.S. (2009) Research for the Interpretation Principle to the Formatted Clause of Insurance Contract-Discussed the Revised Value for the Article 30st of New Insurance Law. Journal of Insurance Research, 12, 110-114. http://bxyi.journalsystem.net/ch/index.aspx

[5] Knox, M.R. (1985) Insurance Contract: Rule of Construction, Judicial, Consumerism, and Coverage. 1st Edition, New L.J., London. 